\title{
Gestation and its Influence on Feeding
}

\author{
Natalia Sales de Carvalho*1 and Daniela Vasconcelos de Azevedo ${ }^{2}$ \\ ${ }^{1}$ Professor of the Nutrition Course at Universidade de Fortaleza. Master's Degree in Nutrition and Health, Brazil \\ ${ }^{2}$ Professor of the Nutrition Course at Universidade Estadual do Ceara. Professor of the MSc in Nutrition and Health at UECE, Brazil
}

Received: February 27, 2018; Published: March 08, 2018

*Corresponding author: Natalia Sales de Carvalho, Professor of the Nutrition Course at Universidade de Fortaleza (UNIFOR). Master's Degree in Nutrition and Health, Brazil, Tel: 55 (85) 98828-4119; Email: natycarvalho_@hotmail.com

\section{Introduction}

The eating habits and choices of pregnant women can be influenced by the innumerable physical and emotional aspects that characterize pregnancy [1]. Healthy eating does not only depend on access to adequate nutritional information. It is necessary that health professionals who work with nutrition education have an expanded view of nutrition, seeking to know which factors may influence the dietary decisions of these women [2-4]. During prenatal care, pregnant women should be understood in an integral manner and not fragmented. Physical and emotional issues should be associated with the family and community context, and with the social relationships. Thus, primary health care professionals must act in the attention to women's health considering all these aspects and establishing a close relation of appreciation of each person's individuality [5]. Food as an integral and fundamental part of the pregnant women's health must also be worked out from this expanded view, especially in nutritional education $[2,4,6]$. In addition to the factors already mentioned, there are other aspects that may influence food habits, such as the pleasure associated with the taste of food, the family's eating habits, the age or stage of psychosocial development, food hygiene, health concerns, philosophical and religious representations about feeding, concerns with the body, among others. It is necessary to know these aspects from a psychological and sociocultural point of view, in order to understand the decision about food choices [2-4].

Feeding prohibitions or restrictions on some foods recommended by health professionals or even imposed by the individual are impregnated with meanings attributed to food. These nutritional guidelines, either for weight reduction or because of the presence of a pathology, in general, bring great difficulties on following the feeding plan. The consequences that this type of food usually entails are the loss of the pleasure of eating, the loss of autonomy and freedom to eat, and an increased desire to eat forbidden foods $[2,4,6,7]$. Thus, proposals to change the food pattern must have alternatives to replace the great food restrictions, preserving the symbolic representations around feeding [2]. A study attempting to investigate the representations of the word "food" for several American generations through the Free Evocation of Words Technique showed that older generations were more concerned with what they consume and with the effects on their health compared to the younger population. Women were even more concerned about food and health than the opposite sex. Thus, it is important to consider the different moments of life of the individual to work with a nutritional education more appropriate to the reality experienced in a given life cycle [4].

Each phase of life influences the determination of the individual's eating behavior. In childhood, for example, the child is able to understand the importance of consuming some food groups, associating that some nutrients are important for their growth. In adolescence, the great importance attributed to the body is more associated with restrictive diets, and this may affect the adolescent health in the development phase4. Gestation is a period marked by innumerable new emotional and physical aspects for women, which may influence eating habits and choices [1]. In the first trimester of pregnancy, episodes of nausea and vomiting, in addition to food cravings and aversions are frequent [1,9]. In the last trimester, anxiety is high, relating it to the proximity of delivery, and pregnancy itself is considered a factor generating anxiety, due to the multiple demands experienced by the woman and the new period $[1,10,11]$.

Primiparous women appear to have a higher level of anxiety, and this fact is related to the new biopsychosocial modifications resulting from pregnancy, in which the women who have already passed through these experiences are more calm [12]. Considering the influence of several factors that can interfere in habit and alimentary behavior, as well as the symbolic representations around the feeding for each group, it is observed the importance of the application and the development of specific strategies of nutritional intervention that can aggregate these values regarding feeding also 
during pregnancy, thus obtaining a greater success in adopting new feeding practices [2]. Only then, actions of nutritional education can become more effective, contributing to the improvement of feeding of these women $[2,3,4,6]$. From these considerations, it is important to broaden the gaze regarding feeding during pregnancy, considering the qualitative aspects of daily feeding, as well as taking into account the psycho-social factors specific to gestation, and how they interfere or influence the feeding of women during that period.

\section{References}

1. Sarmento R, Setubal MSV (2003) Psychological Approach in Obstetrics: emotional aspects of pregnancy, childbirth and the puerperium. Journal of Medical Sciences Campinas 12(3).

2. Garcia RWD (1997) Social Representations of Food and Health and its Impact on Food Behavior Rev Saude Coletiva, Rio de Janeiro 7(2): 51-68.

3. Garcia RWD (2004) Representations on food consumption and its implications in food surveys: qualitative study on subjects submitted to dietary prescription. Rev Nutr Campinas 17(1): 15-28.

4. Viana V (2002) Psychology, health and nutrition: Contribution to the study of eating behavior. Psychological Analysis Lisbon Portugal 4(20): 611-624.

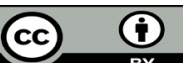

This work is licensed under Creative Commons Attribution 4.0 License

Submission Link: https://biomedres.us/submit-manuscript.php
5. (2012) Ministry of Health Notebooks of Basic Attention - Attention to low risk prenatal care. Brasilia DF, Brazil.

6. Peres DS, Franco LJ, Santos MA (2006)Dietary behavior in women with type 2 diabetes. Rev Saude Publica, Sao Paulo 40(2): 310-317.

7. Bernardi F, Cichelero, C Vitolo MR (2005) Behavior of food restriction and obesity. Rev Nutr Campinas 18(1): 85-93.

8. Rozin P, Kurzer N, Cohen AB (2002) Free associations to food: the effects of gender, generation, and culture. Journal of Research in Personality 36(5): 419-441.

9. Bayley TM, Dye, L Jones, S Bono MD, Hill AJ (2002) Food cravings and aversions during pregnancy: relationshipswith nausea and vomiting. Appetite: Elsevier Science Ltd 38(1): 45-51.

10. Falcone VM, Mader CVN, Nascimento, CFL Santos JMM, Nobrega FJ (2005) Multiprofessional performance and the mental health of pregnant women. Rev. Saude Publica 39(4): 612-618.

11. Pacheco A, Figueiredo B, Costa R, Pais A (2005) Anticipation of labor experience: developmental changes throughout pregnancy. Portuguese Journal of Psychosomatic Porto- Portugal, p. 7.

12. Barros IPM (2004) Psychological characteristics of the first and second pregnancies: the use of DFH and TAT in prenatal care, Dissertation (Master degree) - Department of Clinical Psychology, Institute of Psychology, University of Sao Paulo, Sao Paulo, Brazil.

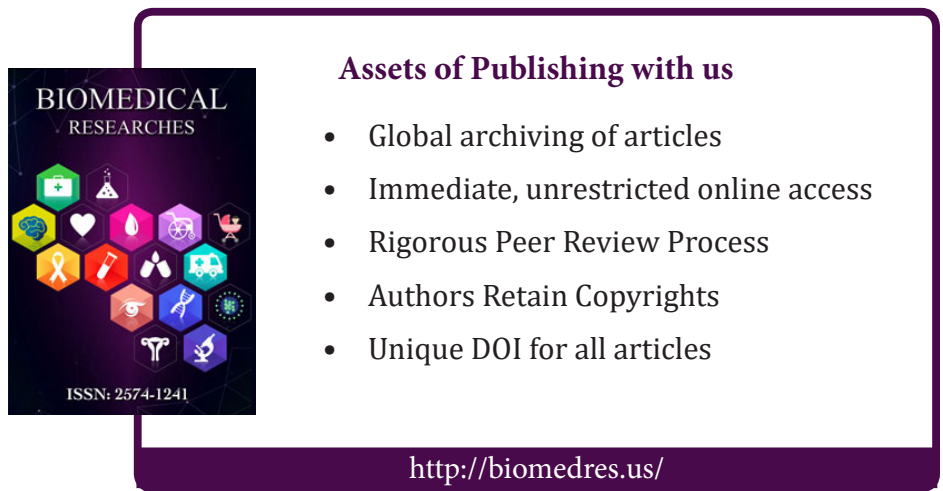

